\title{
BONE MINERAL DENSITY IN UREMIC CHILDREN
}

\author{
$\mathcal{B} y$
Samira Z. Sayed*, Gamal T Soliman*, \\ Mohamed A. Fouda ${ }^{\star *}$, and Ishak, M. Malek***,
}

From

Pediatric department", EL-Minia University, El-Mansoura Urology and Nephrology Center**. And Ministry of Health and Population ***

\begin{abstract}
Background: In Patients with chronic renal failure (CRF), metabolic bone disease is a common complication. Osteopenia is frequently reported in adult CRF patients, and after transplantation. However, reports on bone mineral density (BMD) and bone metabolism in children are rather sparse.
\end{abstract}

Objective: The aim of this work was to study BMD in a group of children with end-stage renal failure, and to relate their BMD to some markers of bone metabolism.

Methods: Measurements of serum calcium, phosphorus, alkaline phosphatase (AP), calcitonin (CT) and parathyroid hormone (PTH) were performed in 25 children aged $9.85 \pm 3.44$ years with end-stage renal failure ( 11 males and 14 females), and in 15 age 19 and sex matched controls. Measurement of bone mineral density (BMD) was performed for patients and controls using quantitative computed tomography.

Results: Our results showed that serum calcium was significantly lower, while serum levels of phosphorus and AP were significantly higher compared with controls. Plasma CT levels were significantly higher in CRF patients in comparison to controls $(29.7 \pm 7.3$ vs $13.8 \pm 4.1 \mathrm{pg} / \mathrm{ml}, p<0.01)$. PTH levels were significantly higher in CRF patients compared with controls (413.7 \pm 113.4 vs $12.1 \pm 6.1, p<0.0001)$. BMD was slightly lower in CRF patients compared with controls $\left(141.2 \pm 26.5\right.$ vs $\left.150.3 \pm 33.5 \mathrm{gm} / \mathrm{cm}^{3}\right)$, but the difference was not statistically significant. These pararneters did not differ significantly between patients undergoing hemodialysis and those MANSOURA MEDICAL JOURNAL 
undergoing continuous ambulatory peritoneal dialysis (CAPD). BMD correlated significantly with serum levels of $\mathrm{AP}, \mathrm{CT}$, and PTH.

Conclusion: BMD in our patients didn't differ significantly from healthy children, This may be attributed to adequate treatment with $\alpha$-calcidiol or the short duration of renal failure compared with adult patients.

Key Words: Chronic renal failure Dialysis - Renal bone disease - Bone mineral density

\section{INTRODUCTION}

Secondary hyperparathyroidism is a frequent complication of chronic renal failure (CRF) and a major factor in the pathogenesis of renal osteodystrophy. A high serum phosphate, decreased levels of serum $1,25(\mathrm{OH})_{2}$ $D_{3}$ and the subsequently low serum calcium are the major metabolic abnormalities in CRF, which lead to the secondary hyperparathyroidism1. Many children responded to daily vitamin $D$ therapy; however, progression ct secondary hyperparathyroidism has been reported in a substantial proportion of pediatric patients undergoing maintenance dialysis therapy2.

Vol. 32, No. 1 \& 2 Jan. \& April, 2001
The term "renal osteodystrophy" is reserved for diseases affecting the control of bone modeling with high or low bone turnover ${ }^{3}$. Secondary hyperparathyroidism plays a central role in the pathogenesis of high-turnover disease, whereas adynamic bone disease and osteomalacia are examples of low-turnover disease 4 . Osteopenia is frequently reported in adult CRF patients 5,6 , and after transplantation 7 . However, reports on bone mineral density (BMD) and bone metabolism in children are rather sparse 8 .

Classical $\mathrm{x}$-ray has been traditionally used for bone imaging. However, it is not sensitive enough to detect early changes in bone structure, because pathology becomes evident when $30-40 \%$ of bone mineral is already lost 9 . Quantitative Computed Tomography (QCT) is a more recent addition to the field of bone mineral analysis. It can identify the absolute mineral content of a specific volume of bone. It offers noninvasive determination of vertebral bone mineral content with exact three-dimensional localization of the measurement site, and separation of cortical from trabecular bone 10 .

The aim of this work was to study 
bone mineral density (BMD) in a group of children with CRF, and to relate their BMD to some markers of bone metabolism.

\section{PATIENTS AND METHODS}

This study was carried out at Mansoura Urology and Nephrology Center and included 25 children (14 males and 11 females) with chronic renal failure, their ages ranged from 3.5 to 15 years $(9.85 \pm 3.44$ ys). Nineteen children were treated with hemodialysis 9-12 $\mathrm{h}$ a week, and 6 children with continuous ambulatory peritoneal dialysis (CAPD) with 4-6 exchanges of dialysate daily. The cause of renal failure was chronic glomerulosclerosis in 9 cases, chronic pyelonephritis in 4 cases, hereditary nephritis in 2 cases, nephrocalcinosis in 2 cases, hemolytic uremic syndrome in 2 cases, and not identified in 6 cases. Fifteen apparently healthy, children were included as a control group, they were selected from the outpatient clinic complaining from minor surgical problems, they were 8 males and $7 \mathrm{fe}$ males, and their ages ranged from 5 to 15 years $(8.80 \pm 3.36 \mathrm{ys})$.

All patients were subjected to careful history taking and thorough clinical examination including age, sex, disease duration, type of treatment and its duration, edema, hypertension, pallor, growth retardation, bone deformities and muscle weakness. Disease duration ranged from 25 to 60 month ( $32.4 \pm 6.4$ months), and duration of dialysis treatment ranged from 10 to 24 months (14.1 \pm 3.4 months).

One $\alpha$-hydroxyvitamin $D_{3}$ ( $\alpha$. calcidiol) and calcium carbonate were administered daily to children at doses of $0.05 \mu \mathrm{g} / \mathrm{kg} / \mathrm{day}$, and $50-100 \mathrm{mg} /$ $\mathrm{kg} /$ day respectively. Doses were adjusted according to levels of serum calcium and phosphorus.

Estimation of parathormone (PTH) level in the serum was performed by multivalent radioimmunoassay using commercially available ELISA kits (R\&D system, Minneapolis, MN, USA).

Calcitonin (CT) was analyzed by radioimmunoassay with double antibodies, in liquid phase (Nichols Institute Diagnostics, California, USA).

Determination of serum creatinine, calcium, phosphorus, and alkaline phosphatase levels was carried out 
by standard laboratory techniques using Hitachi 771 autoanalyzer (Boehringer Mannheim).

Measurement of bone mineral density (BMD) was done for all patients and controls using quantitative computed tomography (QCT). This was made using G.E. prospeed plus with $512 \times 512$ matrix and solid state phantom containing $0 \mathrm{mg} / \mathrm{cc}, 75 \mathrm{mg} / \mathrm{cc}$ and $150 \mathrm{mg} / \mathrm{cc}$ of calcium hydroxyapatite. The density of the selected area of interest within a slice through a vertebral body is measured in Houndsfield units (HU), also known as $\mathrm{CT}$ number where water $=0 \mathrm{HU}$ and air $=-100 \mathrm{HU}$. Conversion to $\mathrm{gm} / \mathrm{cm}^{3}$ is made by comparing the $C T$ number of the trabecular bone to that of the compartment of the calibration standard. The calculated densities of the vertebrae are averaged and compared to those of a normal population 11 .

\section{STATISTICAL METHODS}

Data were expressed as mean \pm standard deviation (Mean $\pm S D$ ) for parametric variables. Comparisons between groups were done by student's t-test (parametric) and chisquare test (non-parametric) when appropriate. For measurement of line- ar relations, Pearson's correlation coefficient was considered.

\section{RESULTS}

Mean serum levels \pm standard deviation $(\mathrm{M} \pm \mathrm{SD}$ ) of calcium, phosphorus, alkaline phosphatase (AP), calcitonin (CT), parathormone (PTH), and bone mineral density (BMD) are shown in table (1).

Serum calcium levels were significantly lower in CRF patients compared with controls $(p<0.05)$. Serum levels of phosphorus, AP, CT, PTH were significantly higher in CRF patients compared with controls.

For phosphorus: $5.89 \pm 0.73$ vs $4.95 \pm 0.68 \mathrm{mg} / \mathrm{dl}, p<0.05$. For AP: $173.9 \pm 15.4$ vs $26.6 \pm 5.5 \mathrm{IU} / \mathrm{dl}$, $p<0.001$. For CT: $29.7 \pm 7.3$ vs $13.8 \pm 4.1 \mathrm{pg} / \mathrm{dl}, \mathrm{p}<0.01$. For $\mathrm{PTH}$ : $413.7 \pm 113.4$ vs $12.1 \pm 6.1 \mathrm{pg} / \mathrm{dl}$, $p<0.0001$. No major difference was evident in BMD values in comparison with controls although levels were slightly lower in our patients.

Table (2) shows results of comparison between patients undergoing hemodialysis (19 patients) and those undergoing CAPD (6 patients) as regard $B M D$ and biochemical

Vol. 32, No. 1 \& 2 Jan. \& April, 2001 
variables studied. It is evident that no significant differences can be detected between the two groups regarding any of the studied parameters.

Disease duration correlated negatively with both serum calcium and
$B M D$, and correlated positively with serum phosphorus, AP, CT, and PTH, but correlations did not reach significant levels (table 3 ). BMD correlated negatively with AP $(r=0.674, p<$ 0.01), $C T(r=0.550, p<0.05)$ and PTH $(r=0.666, p<0.001)$; as shown in table (4) and figures (1-3).

Table (1): Mean \pm standard deviation (MISD) of serum calcium, phosphorus, alkaline phosphatase, calcitonin, PTH, and BMD in CRF patients and conirols:

\begin{tabular}{|l|c|c|c|c|c|}
\hline \multirow{2}{*}{} & \multicolumn{2}{|c|}{$\begin{array}{c}\text { Patients } \\
\mathrm{n}=25\end{array}$} & \multicolumn{2}{c|}{$\begin{array}{c}\text { Controls } \\
n=15\end{array}$} & \multirow{2}{*}{$\mathrm{P}$} \\
\cline { 2 - 6 } & Mean & SD & M & SD & \\
\hline Calcium $(\mathrm{mg} / \mathrm{dl})$ & 8.17 & 0.50 & 9.90 & 0.80 & $<0.05$ \\
\hline Phosphorus $(\mathrm{mg} / \mathrm{dl})$ & 5.89 & 0.73 & 4.95 & 0.68 & $<0.05$ \\
\hline Alk.phosph. $(I U / d l)$ & 173.9 & 15.4 & 26.6 & 5.5 & $<0.001$ \\
\hline Calcitonin $(\mathrm{pg} / \mathrm{ml})$ & 29.7 & 7.3 & 13.8 & 4.1 & $<0.01$ \\
\hline PTH $(\mathrm{pg} / \mathrm{dl})$ & 413.7 & 113.4 & 12.1 & 6.1 & $<0.0001$ \\
\hline BMD $\left(\mathrm{gm} / \mathrm{cm}^{3}\right)$ & 141.2 & 26.5 & 150.3 & 33.5 & NS \\
\hline
\end{tabular}


Table (2): Comparison between hemodialysis and CAPD patients as regard BMD and biochemical variables $(M \pm \mathrm{SD})$ :

\begin{tabular}{|l|c|c|c|}
\hline & $\begin{array}{c}\text { Hemodialysis } \\
(\mathrm{n}=19)\end{array}$ & $\begin{array}{c}\text { CAPD } \\
(\mathrm{n}=6)\end{array}$ & $\mathrm{P}$ \\
\hline Calcium $(\mathrm{mg} / \mathrm{dl})$ & $8.07 \pm 0.45$ & $8.47 \pm 0.55$ & NS \\
\hline Phosphorus $(\mathrm{mg} / \mathrm{dl})$ & $5.89 \pm 0.73$ & $5.01 \pm 0.94$ & $\mathrm{NS}$ \\
\hline Alk.phosph $(I \mathrm{U} / \mathrm{dl})$. & $180.9 \pm 25.4$ & $173.9 \pm 18.4$ & $\mathrm{NS}$ \\
\hline Calcitonin $(\mathrm{pg} / \mathrm{dl})$ & $27.8 \pm 8.5$ & $32.0 \pm 11.2$ & NS \\
\hline PTH $(p g / d l)$ & $433.7 \pm 183.7$ & $393.7 \pm 153.4$ & NS \\
\hline BMD $(m g / d l)$ & $140.2 \pm 48.5$ & $155.2 \pm 31.5$ & NS \\
\hline
\end{tabular}

Table (3): Correlation between disease duration and biochemical variables in patients with CRF.

\begin{tabular}{|l|c|c|}
\hline & $R$ & $P$ \\
\hline Calcium & -0.307 & NS \\
\hline Phosphorus & 0.007 & NS \\
\hline Alk.Phosphatase & 0.027 & NS \\
\hline Calcitonin & 0.130 & NS \\
\hline Parathormone & 0.090 & NS \\
\hline Bone Density & -0.064 & NS \\
\hline
\end{tabular}

Table (4): Correlation between bone density and biochemical variables in patients with $C R F$ :

\begin{tabular}{|l|c|c|}
\hline & $\mathrm{R}$ & $\mathrm{P}$ \\
\hline Calcium & 0.260 & $\mathrm{NS}$ \\
\hline Phosphorus & -0.257 & $\mathrm{NS}$ \\
\hline Alk.Phosphatase & -0.647 & $<0.01$ \\
\hline Calcitonin & -0.550 & $<0.05$ \\
\hline Parathormone & -0.666 & $<0.001$ \\
\hline
\end{tabular}

Vol. 32, No. 1 \& 2 Jan. \& April, 2001 
Samira Z. Sayed et al ...

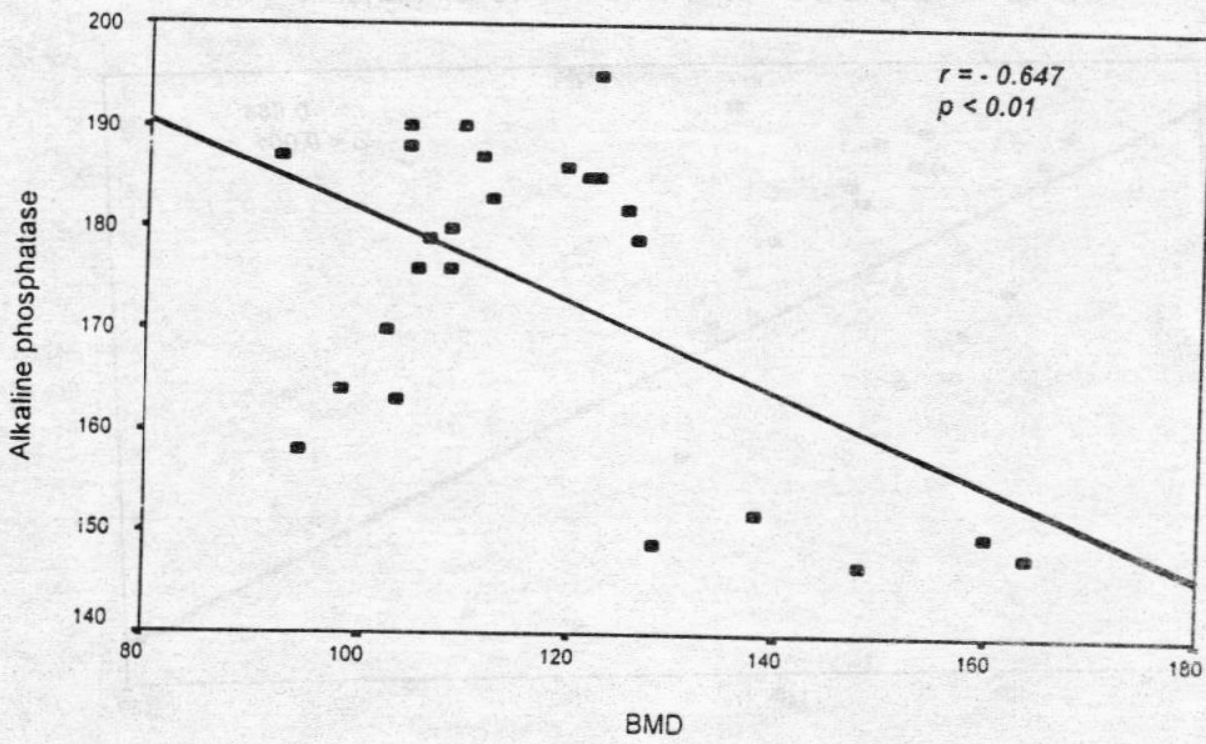

Fig. 1 : Correlation between BMD and alkaline phosphatase.

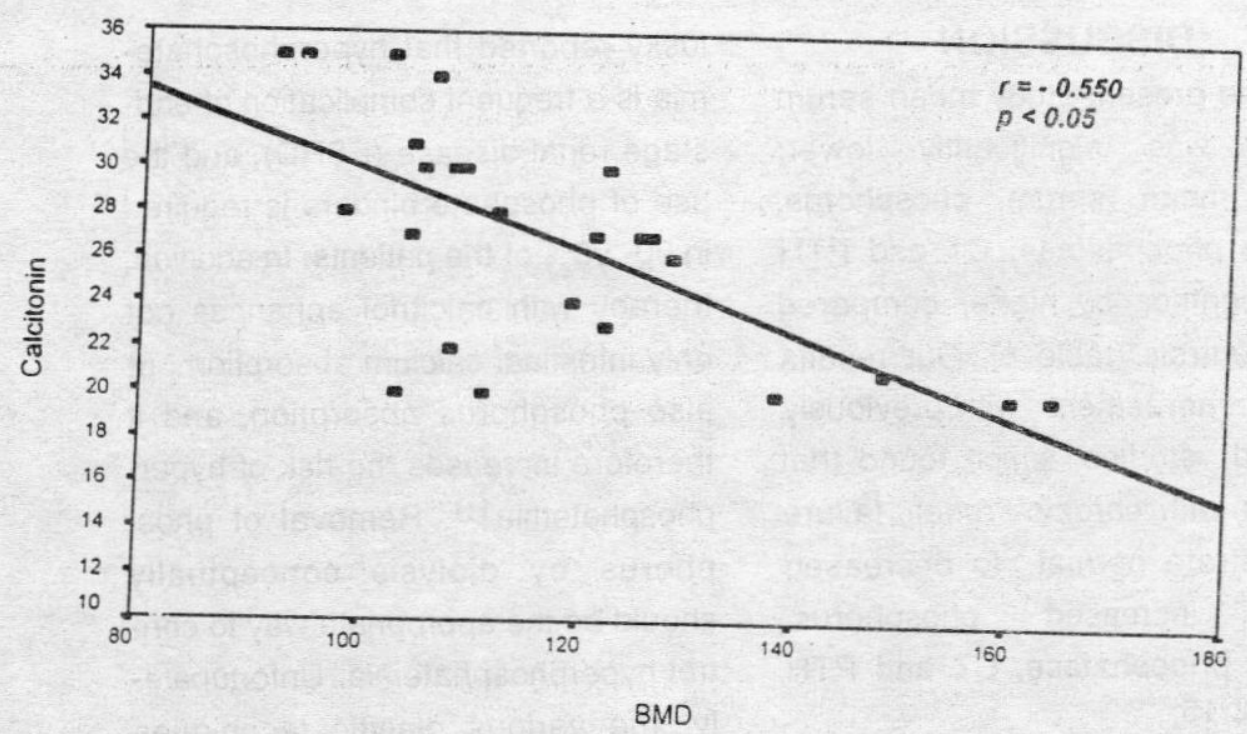

Fig. 2 : Correlation between BMD and calcitonin.

MANSOURA MEDICAL JOURNAL 


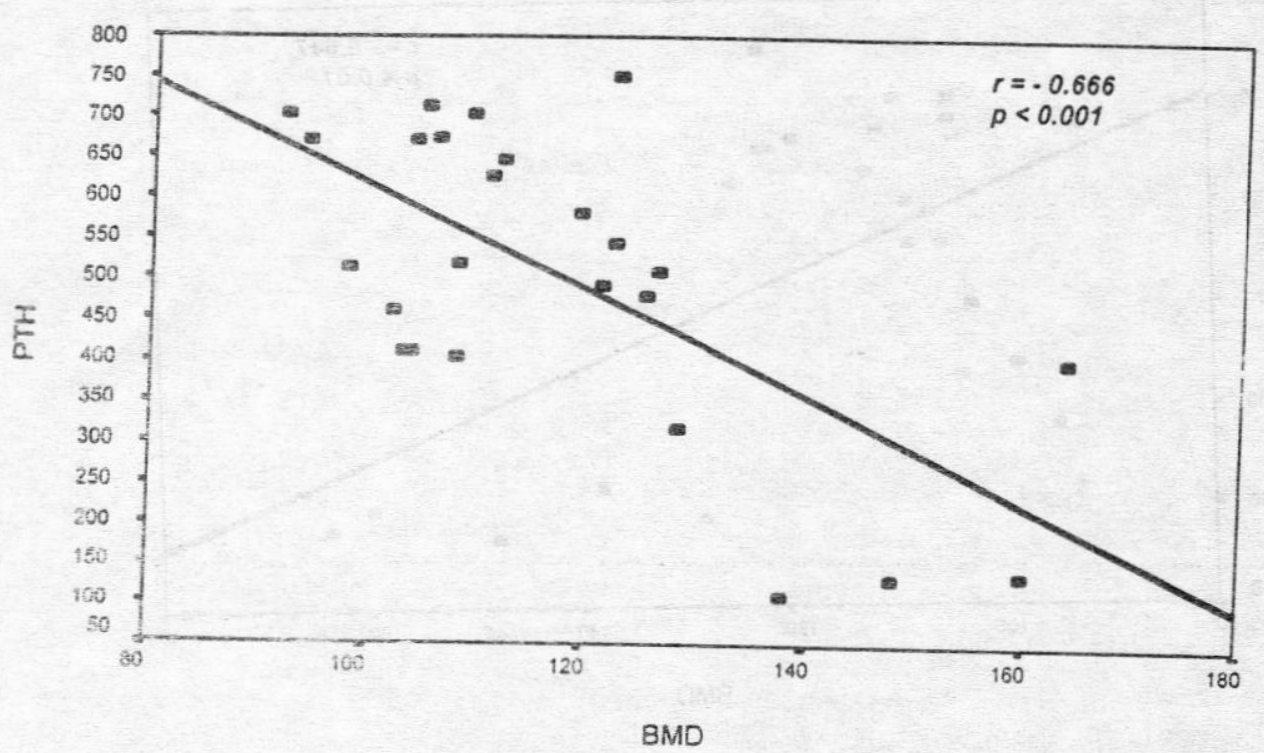

Fig. 3 : Correlation between BMD and PTH.

\section{DISCUSSION}

In the present study mean serum calcium was significantly lower, and mean serum phosphorus, alkaline phosphatase, CT and PTH were significantiy higher compared with controls (table 1). Our results are in agreement with previously reported studies, which found that patients with chronic renal failure demonstrate normal to decreased calcium, increased phosphorus, alkaline phosphatase, CT and PTH leveis $12-15$.

In agreement with our results, Sa- lusky reported that hyperphosphate$\mathrm{mia}$ is a frequent complication of endstage renal disease (ESRD), and the use of phosphate binders is required in $90-95 \%$ of the patients. In addition, therapy with calcitriol enhances not only intestinal calcium absorption but also phosphorus absorption, and it therefore increases the risk of hyperphosphatemia13. Removal of phosphorus by dialysis conceptually should be the appropriate way to control hyperphosphatemia. Unfortunately, the various dialytic techniques available can not achieve this goal, and CAPD in general is not better

Vol. 32, No. 1 \& 2 Jan. \& April, 2001 
than hemodialysis in removing phosphorus 15 .

Serum calcium levels often are decreased in patients with advanced renal failure, and wide variations exist among individual patients. Hypocalcemia may result from hyperphosphatemia, inadequate dietary intake, and decreased intestinal calcium absorption caused by a deficiency in the active form of vitamin D: 1,25 $(\mathrm{OH})_{2} \mathrm{D}_{3}{ }^{12}$ : Some patients who are maintained on peritoneal dialysis may have persistently low to normal serum calcium, necessitating initiation of calcium supplementation or vitamin D therapy 14 . However, in some patients treated with continuous peritoneai dialysis without vitamin D therapy, serum calcium levels are norma! or slightly above normait 6 .

Alkaline phosphatase (AP) is a glycosylated protein produced by at least 5 different organs: liver, bone, kidney, intestine, andplacenta. in bone, AP is produced by osteoblsts and osteoblast precursors, and participates in the mineralization process 17 . It is a useful index to detect the progression of secondary hyperparathyroidism and a guide for therapy with calcitriol13. Its activity has been shown to correlate with the histologic features of osteitis fibrosa18. Measurement of the bonespecific AP (bAP) was found to better correlate with bone formation and bone resorption histomorphometric parameters than intact $\mathrm{PTH}$ or total AP19.

Our results showed that serum CT leveis were significantly higher in CRF patients compared with controls (table 1). This is in agreement with Messa et al who found that serum CT levels increased progressively with the falling of GFR values, even though in the absence of detectable changes in calcium concentrations 20 . They postulated that higher CT levels might depend on retention of inactive forms of the hormone secondary to decreased GFR reduction or stimulation of parathyroid $C$ cells by increased PTH or some other factors connected to GFR reduction to produce $\mathrm{CT}^{20}$. Tomita and Millard found $\mathrm{C}$-cell hyperplasia in. $58 \%$ of thyroid glands removed from uremic patients, as compared to $36 \%$ in glands removed from primary hyperparathyroidism 21 . Whatever the cause of the CT increase, it might be hypothesized that its increased serum levels contribute to skeletal resistance to PTH action, as suggested by ani-

MANSOURA MEDICAL JOURNAL 
mal studies and /or direct PTH stimulation, as supported by in vitro studies 20 .

Our results showed that PTH levels were significantly elevated in CRF patients compared with controls (table 1), and this is in agreement with Siatopolsky who found that secondary hyperparathyroidism is a universal complication in patients with $\mathrm{CRF}$ and reported that abnormal calcium, phosphorus and vitamin $D$ metabolism in CRF play a key role in its development 22 . Secondary hyperparathyroidism remains the most common type of renal bone disease found in hemodialysis patients either in isolation or as part of mixed renal osteodystrophy 13,23 .

Secondary hyperparathyroidism is composed of increased PTH synthesis and secretion due to an increase in PTH gene expression and parathyroid cell proliferation. PTH gene expression is regulated by calcium, phosphate, and $1,25(\mathrm{OH})_{2} \mathrm{D}_{3} 24$. The contribution of hyperphosphatemia to the pathogenesis of secondary hyperparathyroidism of CRF has been documented for many years 25 , but it was never possible to separate the effect of hyperphosphatemia from the Vol. 32, No. 1 \& 2 Jan. \& April, 2001 secondary decreases in serum calcium and $1,25(\mathrm{OH})_{2} \mathrm{D}_{3} 26$. This was first established by the work of Kilav et al who succeeded in demonstrating that the effect of serum phosphate on PTH gene expression and serum PTH levels was independent of any changes in serum calcium or 1,25 $(\mathrm{OH})_{2} \mathrm{D}_{3} 27$.

Also, our results are in agreement with Salusky who reported that serum PTH levels are often substantially elevated in patients with advanced renal failure, which suggests the presence of secondary hyperparathyroidism 13 . Mathias and coworkers demonstrated the use of the immunoradiometric PTH assay in distinguishing between low-to normal and high indices of bone formation in adolescents and young adults treated with maintenance hemodialysis 28 , and similar results have been published concerning adults treated with hemodialysis or peritoneal dialysis 29,30 . The authors have characterized PTH values in patients undergoing peritoneal dialysis and treated with calcium carbonate and daily calcitriol at the time of bone biopsy31. Under such treatment, serum PTH levels of more than $200 \mathrm{pg} /$ $\mathrm{mL}$ strongly suggested the presence of high-turnover lesion of bone in 
most patients with bone biopsy evidence of secondary hyperparathyroidism. On the other hand, none of the patients with adynamic lesions of bone had values above this thres. hold31.

Surprisingly, we didn't find a significant difference between our patients and controls as regard BMD although levels in renal failure patients were slightly lower (table 1). This is in variance with the results of Bianchi et al and Gabay et al who reported decreased BMD in adult CRF patients on conservative treatment or dialysis 5,6 . The proximal tubule is the primary site of calcitriol synthesis by the enzyme $1 \alpha$-hydroxylase. In CRF a significant reduction in calcitriol synthesis occurs. Administration of calcitriol proved to be an effective treatment of secondary hyperparathyroidism 32 . Adequate treatment with 1 $\alpha$-calcidiol might have prevented osteopenia in our patients. Furthermore, the shorter duration of CRF in our patients may explain the discrepancy between our results and the reduced BMD found in adult patients.

Also, our results are in variance with Taal et al who found a moderate reduction in mean BMD in their unse- lected population of chronic hemodialysis patients 23 , and with several other studies in adult patients using different methods of bone density measurements33-35.

However, our results are in agreement with van der Sluis et al who found that mean BMD of children with CRF didn't differ from normal, and they found even increased bone mineral apparent density (BMAD) of lumbar spine in children with CRF. They attributed this to adequate treatment with $\alpha$-calcidiol in addition to the short duration of renal failure in pediatric patients $^{3}$. Few studies have addressed the issue of calcium supplementation in hemodialysis patients, although oral $1 \alpha$-hydroxycalciferol treatment has been shown to prevent the loss of BMD at the lumbar spine in 165 male patients 36 .

In our study, levels of calcium, phosphorus, AP, CT, PTH, and BMD didn't differ significantly between patients treated with either hemodialysis or CAPD (table 2). These results are in agreement with the results of Ziolkowska et al who did not find significant differences in the prevalence of particular types of osteodystrophy in relation to dialysis type 37 . Howev- 
er, our results are in variance with the results of Sherrard et al who reported that a different pattern of bone lesions is seen in peritoneal dialysis (PD) as compared with hemodialysis (HD), with low-turnover disorders comprising $66 \%$ of the lesions seen in PD and high-turnover lesions accounting for $62 \%$ of the bone histologic findings in HD. They attributed these findings to alterations in PTH leveis, as mean PTH leveis in their HD patients were 2.5 times the levels found in PD patients, while in older age, higher prevalence of diabetes and a shorter duration of dialysis may also have contributed to the findings in PD patients. They suggested that PD, perhaps by maintaining calcium at higher levels, may more effectively suppress the parathyroid gland 30 . However their study was carried out on adult patients (mean $\pm S D$ of age: $57.4 \pm 4.3$ years), with different clinical criteria and different duration of renal failure and dialysis therapy compared with other patients, and this may explain the discrepancy between our results.

Cortical porosity is increased in hyperparathyroidism 38 , and it is therefore not surprising that serum PTH is an important determinant of BMD. As can be seen from table (4) Vol. 32, No. 1 \& 2 Jan. \& April, 2001 and figures (1-3), serum $C T, P T H$ and AP were negatively carrelated with BMD measurements. Our results are in agreement with several investigators who reported a similar negative association between PTH using a variety of measurements of $\mathrm{BMD}^{39-41}$. Also, our results are in agreement with Ziolkowska et al who were evaluating the usefulness of particular bone formation markers, They reported that PTH and AP correlate with bone formation rate, and concluded that determination of AP activity is clinically useful in the evaluation of bone metabolism 37 . Messa et al reported that progressive increase in $\mathrm{PTH}$ secretion was found to be affected by $\mathrm{CT}$, and hypothesized that increased $\mathrm{CT}$ levels might be related in some way to increased PTH secretion. Whether the link between CT and PTH secretion is a cause-effect or both hormones are dependent on a common factor was unclear20.

Other studies, however, have been unable to show a negative association between PTH levels and $B M D 33,38$. While this may be explained by the small number of patients or the use of C-terminal PTH assays in some of the studies, it suggests that other factors affect BMD in 
hemodialysis patients as age and body weight 23 . Also, we didn't find any significant correlation between disease duration and BMD or any of the variables studied (table 3). van der Sluis et al found similar results, and could nol find any tendency to reduced BMD in those of their patients with a longer duration of the disease. They suggested that this might be explained by the relatively short duration of the disease in children compared to adult patients 3 .

In conclusion, we have demonstrated that BMD of children with CRF did not differ from healthy children. The absence of osteopenia in our pediatric patients may be related to the relatively short duration of CRF compared to adult. Furthermore, improved treatment with $\alpha$-calcidiol may play a role. BMD correlated significantly with $A P, C T$ and $P T H$, but not with disease duration owing to the relatively short duration of CRF in our pediatric patients.

\section{REFERENCES}

1- Silver S, Kilav R, Sela-Brown A et a. (2000) : Molecular mechanisms of secondary hyperparathyroidism. Pediatr Nephrol; 14: 626-628.
2- Salusky IB, Coburn JW, Brill J et al. (1988) : Bone disease in pediatric patients undergoing dialysis with CAPD or CCPD. Kidney Int; 33: 975 982.

3- van der Sluis IM, Boot AM, Nauta $J$ et al. (2000) : Bone density and body composition in chronic renal failure: effects of growth hormone treatment. Pediatr Nephrol; 15 :221-28 .

4- Lindberg JS, Moe SM. (1999) : Osteoporosis in end-stage renal disease. Semin Nephrol; 19:115-22.

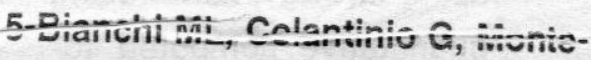
sano $A$ et al. (1992) : Bone mass status in different deỹiese of of chronir renal failure. Bone; 13: 225-28.

6- Gabay G, Ruedin P, Slosman D et al. (1993) : Bone mineral density in patients with endstage renal failure. Am J Nephrol ; 13:115-23.

7- Cueto-Manzano AM, Konel S, Hutchison AJ et al. (1999) MANSOURA MEDICAL JOURNAL 
: Bone loss in longterm renal transplantation: histopathology and densitometry analysis. Kidney Int; 55:2021-29.

8- Lanes $\mathrm{R}$, Gunczler $\mathrm{P}$, Orta $\mathrm{N}$ et al. (1996) : Changes in bone mineral density, growth velocity and renal function of prepubertal uremic children during growth hormone treatment. Horm Res; 46:263-68.

9- Peel N, and Eastell R. (1995) : Osteoporosis. BMJ; 310: 989-992.

10- Khalil OA. (1997) : Bone minera! measurement in the lumbar spine cf Egyptians using quaniitaiive cúminputed tomography. Egyp. J Radiol Nuc Med; 18(2): 445-51.

11- Block JE, Smith R, Gluer CC et al. (1989) : Models of spinal trabecular bone loss as determined by quantitative computed tomography. $J$ Bone Miner Res; 4: 249 257.

12- Bergstein JM. (2000) : Renal fail- ure in: Behrman RE, Kliegman RM, and Jenson $H B$ (eds.): "Neison Textbook of Pediatrics" $16^{\text {th }}$ ed. WB Saunders Company, Philadelphia, 2000; chapter 543 , P:1611.

13- Salusky IB. (1995) : Bone and mineral metabolism in childhood end-stage renal disease. Pediatr Clin North Am; (6) $42: 1531-50$
14- Sanchez CP, Goodman WG, Salusky IB. (1999) : Osteodystrophy in: Barratt TM, Avner ED, Harman WE (eds.) "Pediatric Nephrology" 4th ed. Lippincott Williams \& Wilkins, 1231$4 \hat{0}$

15- Llash F and Yudd M. (1998) : The importance of hyperphosphatemia in the severity of hyperparathyroidism and its treatment in patients with chronic renal failure. Nephrol Dial Transplant; 13 (Suppl 3): 5761.

16- Cann EC. (1988) : Quantitative computed tomography for

Vol. 32, No. 1 \& 2 Jan. \& April, 2001 
determination of bone mineral density: a review. Radiology; 166: 509-22.

17- Ferreira A. (1998) : Biochemical markers of bone turnover in the diagnosis of renal osteodystrophy: what do we have, what do we need? Nephrol Dial Transplant; 13 (Suppl 3): 29-32.

18- Pierides $A M$, Skillen AW, Ellis HA. (1979) : Serum alkaline phosphatase in azotemic and hemodialysis osteodystrophy: A study of isoenzyme patterns, their correlation with bone histology, and their changes in response to treatment with $l \alpha(\mathrm{OH}) D_{3}$ and $1,25\left(\mathrm{OH}_{2} \mathrm{D}_{3}\right.$. J Lab Clin Med; 93: 899

19- Urena P, Hruby M, Ferreira A et al. (1996) : Plasma total versus bone alkaline phosphatase as markers of bone turnover in hemodialysis , atients. J Am Soc Nephrol; 7: 1-7.

20- Messa P, Vallone C, Mioni G et al. (1994) : Direct in vivo as- sessment of parathyroid hormone-calcium relationship curve in renal patients. Kidney Int, 46:1713.

21- Tomita T, Millard DM. (1992) : C-cell hyperplasia in secondary hyperparathyroidism. Histopathology; 21:469-74.

22- Slatopolsky E. (1998) : The role of calcium, phosphorus and vitamin $D$ metabolism in the development of secondary hyperparathyroidism. Nephrol Dial Transplant; 13 (Suppl 3): 3-8.

23- Taal MW, Masud T, Green D et al. (1999) : Risk factors for reduced bone density in hemodialysis patients. Nephrol Dial Transplant; 14: $1922-28$.

24- Silver J, Yalsindag, C, SelaBrown A et al. (1999) : Regulation of the parathyroid hormone gene by vitamin D, calcium, and phosphate. Kidney Int; 56, supp(73): S2-S7.

25- Slatopolsky E, Bricker NS. MANSOURA MEDICAL JOURNAL 
(1973): The role of phosphorus restriction in the prevention of secondary hyperparathyroidism in chronic renal disease. Kidney Int; 4:141-45.

26- -ilver S, Kronenberg HM. (1996) : Parathyroid hormone-molecular biology and regulation. In: Bilezikian JB, Raisz LG, Rodan GA (eds.): Principles of Bone Biology, San Diego, Academic Press.

27- Kilav R, Silver J, Naveh-Many T. (1995) : Parathormone hormone gene expression in hypophosphatemic rats. J Clin Invest; 96: 327-33.

28- Mathias RS, Salusky IB, Harmon WM et al. (1993) : Renal bone disease in pediatric patients and young adults treated by hemodialysis in a children's hospital. J Am Soc Nephrol; 12: 1938.

29- Pei Y, Hercz G, Greenwood C et al. (1992) : Non-invasive prediction of aluminum bone disease in hemo- and perito-

Vol. 32, No. 1 \& 2 Jan. \& April, 2001 neal dialysis patients. Kidney Int; 41: 1374.

30- Sherrard DJ, Hercz G, Pei Y et al. (1993) : The spectrum of bone disease in end-stage renal failure-An evolving disorder. Kidney Int; 43: 436.

31. Salusky IB, Ramirez JA, Oppenheim WL et al. (1994) : Biochemical markers of renal osteodystrophy in pediatric patients undergoing CAPD/CCPD. Kidney Int; 45: 523 .

32- Hamdy NA, Kanis JA, Beneton MN et al. (1995) : Effect of alphacalcidiol on natural course of renal bone disease in mild to moderate renal failure. BMJ; 310: 45863.

33- Lechleitner P, Krimbacher E, Genser $N$ et al. (1994) : Bone mineral densitometry in dialyzed patients: quantitative computed tomography versus dual photon absorptiometry. Bone; 15: 387-91.

34- Stein MS, Packman DK, Ebel- 
ing PR et al. (1996) : Prevalence and risk factors for osteopenia in dialysis patients. Am J Kidney Dis; 28: 51522.

35- Fletcher S, Jones RG, Rayner $\mathrm{HC}$ et al. (1997) : Assessment of renal osteodystrophy in dialysis patients: use of bone alkaline phosphatase, bone mineral density and parathyroid ultrasound in comparison with bone histology. Nephron; 75: 412-19.

36- Morita A, Tabata $T$, Inoue $T$ et al. (1996) : The effect of oral 1 ahydroxycalciferol treatment on bone mineral density in hemodialysis patients. Clin Nephrol; 46:3 89-93.

37- Ziolkowska H, PanczykTomaszewska M, Debinsk A et al. (2000) : Bone biopsy results and serum bone turnover parameters in uremic children. Acta Pediatr; 89:666-71.
38- Hutchinson AJ, Whitehouse RW, Boulton HF et al. (1993) : Correlation of bone histology with parathyroid hormone, vitamin D3, and radiology in end-stage renal disease. Kidney Int; 44: 1971-77.

39- Asaka M, Lida $\mathrm{H}$, Entani $\mathrm{c}$ et al. (1992) : Total and regional bone mineral density by dual photon absorptiometry in patients on maintenance hemodialysis. Clin Nephrol; 38: 149-53.

40- Foldes AJ, Arnon E, Popovetzer MM. (1996) : Reduced speed of sound in tibial bone of hemodialyzed patients: association with serum PTH level. Nephrol Dial. Transplant; 11:1318-21.

41- Wittich A, Vega E, Casco C et al. (1996) : Ultrasound measurement of the tibia in chronic hemodialysis patients. J Bone Miner Res; 11 (Suppl 1): S247. 


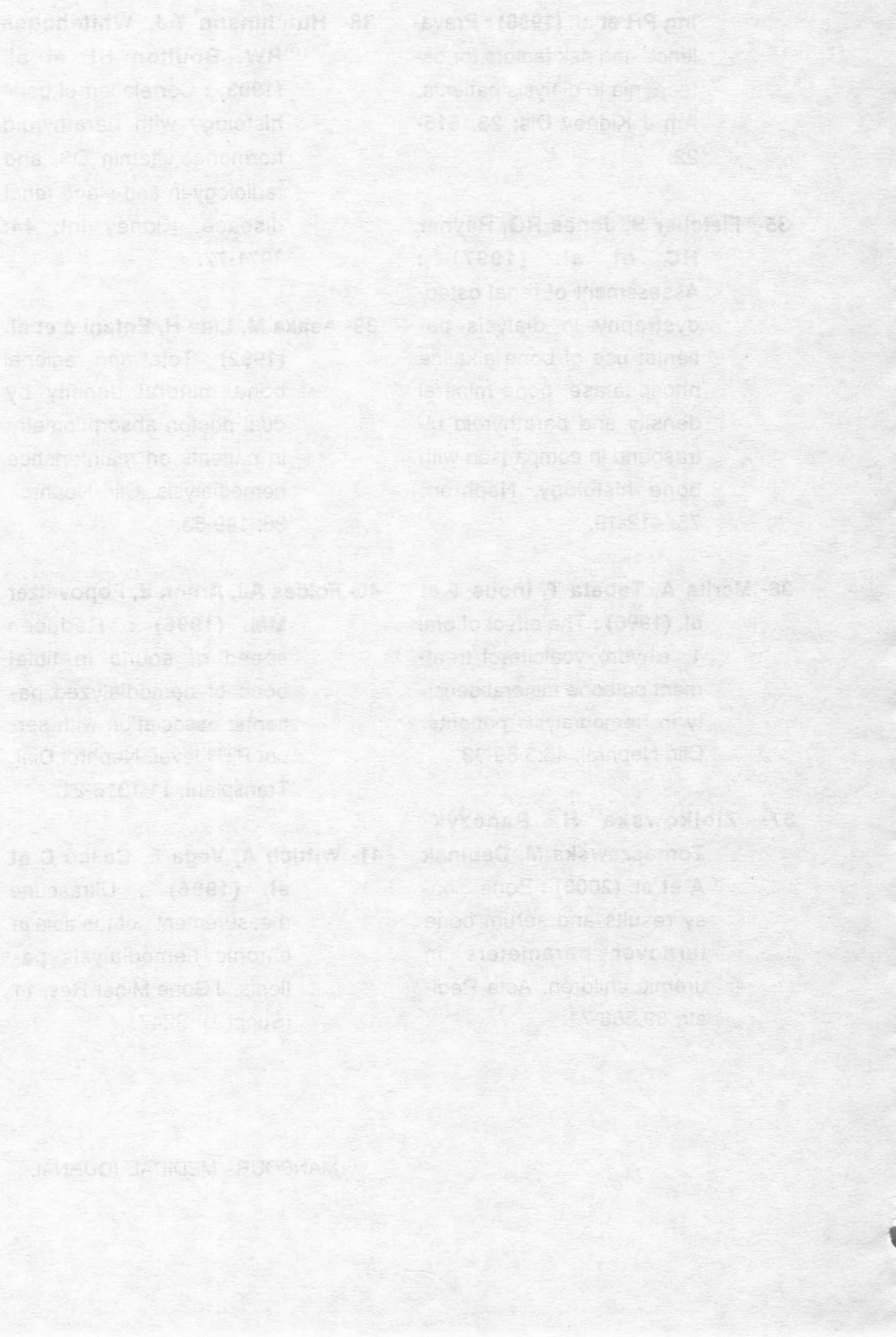

